\title{
EL TRATADO INTERNACIONAL DE LOS PUEBLOS PARA EL CONTROL DE LAS EMPRESAS TRANSNACIONALES
}

\author{
Juan Hernández Zubizarreta \\ Profesor de la UPV/EHU e investigador del Observatorio de Multinacionales en América Latina
} (OMAL)

DOI: $10.1387 /$ lan-harremanak.16108

\section{ABSTRACT}

La arquitectura de la impunidad protege las prácticas de las corporaciones transnacionales y confronta con la arquitectura de los derechos recogida en el Tratado Internacional de los Pueblos para el Control de las empresas Transnacionales. Éste no es un tratado al uso, es una nueva configuración jurídico-política de cómo enfrentar la total impunidad con la que actúan las corporaciones transnacionales.

Palabras clave: arquitectura de la impunidad, arquitectura de los derechos, tratado de los pueblos.

The architecture of impunity protects the practices of transnational corporations and confronts the architecture of rights set down in the International Peoples' Treaty on the Control of Transnational Corporations. This is no ordinary treaty, but a new legal-political approach to confront the total impunity with which transnational corporations act

Keywords: architecture of impunity, architecture of rights, peoples' treaty.

Zigorgabetasunaren arkitekturak korporazio transnazionalen ekintzak babesten ditu eta Enpresa Transnazionalen Kontrolerako Herrien Nazioarteko Itunak 
jasotako eskubideen arkitekturaren kontra egiten du. Hori ez da obiko itun bat, konfigurazio juridiko-politiko berria baizik, korporazio transnazionalen zigorgabetasun jokaerei aurre egin ahal izateko.

Hitz gakoak: zigorgabetasunaren arkitektura, eskubideen arkitektura eta herrien ituna. 


\section{La arquitectura de la impunidad}

Los derechos de las empresas transnacionales se tutelan por un ordenamiento jurídico global basado en reglas de comercio e inversiones cuyas características son imperativas, coercitivas — sanciones, multas, presiones diplomáticas y militares - y ejecutivas, mientras que sus obligaciones se remiten a ordenamientos nacionales sometidos a la lógica neoliberal, a un Derecho Internacional de los Derechos Humanos manifiestamente frágil y a una Responsabilidad Social Corporativa (RSC) voluntaria, unilateral y sin exigibilidad jurídica.

La armadura jurídica de dominación —la Lex Mercatoria o Derecho Corporativo Global - de las corporaciones transnacionales se sustenta sobre principios muy concretos: el de la desregulación de las obligaciones de las empresas transnacionales que se combina con la re-regulación de sus derechos. Es decir, se desregulan los derechos de las mayorías sociales y se re-regulan los derechos del capital (Hernández Cervantes, 2014).

Por otra parte, si en los 90 el neoliberalismo se planteaba reducir el Estado y dejar vía libre a los mercados, ahora se buscan Estados fuertes que garanticen los beneficios de las transnacionales. El Estado es imprescindible para la acumulación de riqueza del capital y para dirigir y reformar la sociedad al servicio de la grandes corporaciones.

En este marco, las empresas transnacionales actúan con un alto grado de impunidad, ya que sus derechos se protegen por un conjunto de contratos, normas de comercio e inversiones de carácter estatal, multilateral, regional y bilateral y de decisiones de los tribunales arbitrales; todas ellas hay que cumplirlas, ya que llevan aparejadas severas sanciones.

Sin embargo, sus obligaciones se reenvían a legislaciones nacionales sometidas a políticas neoliberales de desregulación, privatización y reducción del Estado en políticas públicas. Es decir, se construyen legislaciones ad hoc para la defensa de los intereses de las transnacionales (Hernández Zubizarreta, 2015).

Por otra parte, el Derecho Internacional de los Derechos Humanos y el Derecho Internacional del Trabajo presentan una manifiesta fragilidad para la tutela de los derechos de las mayorías sociales. Los sistemas universales de Dere- 
cho Internacional de los Derechos Humanos y sus jurisdicciones competentes son incapaces de neutralizar el conjunto de disposiciones y sentencias que sustentan la arquitectura de la impunidad formada por los contratos firmados por las empresas transnacionales, las normas, disposiciones, políticas de ajuste y los préstamos condicionados de la Organización Mundial del Comercio (OMC), el Fondo Monetario Internacional (FMI) y el Banco Mundial, los acuerdos y tratados de comercio e inversiones, el Sistema de Solución de Diferencias (SSD) de la OMC y los tribunales arbitrales, como el Centro Internacional de Arreglo de Diferencias relativas a Inversiones (CIADI) del Banco Mundial (Teitelbaum, 2010).

Además, existe una ausencia de mecanismos e instancias adecuadas para exigir la responsabilidad de las empresas transnacionales en el ámbito internacional, ya que los sistemas internacionales y regionales no están diseñados para recibir denuncias contra las empresas y, por otra parte, existe una falta de cumplimiento y ejecución de las decisiones de órganos regionales e internacionales. Por último, la falta de recursos financieros, humanos y técnicos para que las víctimas puedan acceder a los mecanismos de tutela son un gravísimo impedimento.

Es evidente que las empresas transnacionales amplían sus derechos y disfrutan de controles normativos muy deficientes. Las legislaciones de los Estados receptores y los sistemas universales no han evolucionado paralelamente al Derecho Corporativo Global. En el diseño y aprobación de los códigos externos internacionales se distinguieron tres fases.

En la primera, se puso en cuestión la concepción clásica que vincula, sin más, a las empresas multinacionales con efectos positivos sobre el desarrollo; la idea de control normativo sobre las multinacionales fue emergiendo en el ámbito internacional.

En la segunda fase, tuvo lugar una reacción de los países ricos y corporaciones económicas en contra de cualquier código vinculante. Los proyectos de códigos externos de los años setenta fueron desautorizados por la Cámara de Comercio Internacional, que neutralizó cualquier iniciativa pública y elaboró códigos internos, unilaterales y voluntarios cercanos a la RSC, con el objetivo de acallar las protestas ciudadanas ante las prácticas de las transnacionales. En la misma lógica de la voluntariedad, se aprobaron la Declaración Tripartita de principios sobre las empresas multinacionales y la Política Social de la Organización Internacional del Trabajo y las Líneas Directrices de la Organización para la Cooperación y el Desarrollo Económicos (OCDE) para empresas multinacionales.

En la tercera fase, el Global Compact de la ONU — diez principios muy generales y sin ninguna eficacia normativa-, ha abierto paso al marco Ruggie (Hernández y Ramiro, 2015a) y éste a su adaptación a los Estados —en el Es- 
tado Español está pendiente de aprobación el Plan Nacional sobre Empresas y Derechos Humanos (Hernández y Ramiro 2014 y 2015b)—. La ofensiva de la voluntariedad se sofistica jurídicamente, pero su objetivo final sigue siendo la impunidad. En el debate de fondo late una contradicción vinculada a las relaciones de fuerza más que a dificultades técnico jurídicas (Hernández Zubizarreta, 2009).

En los contornos de las realidades jurídicas mencionadas, surge la RSC y los códigos de conducta como fórmula de Derecho Blando para contener el poder de las empresas transnacionales. Las ideas seudo-normativas sobre las que bascula la RSC son la voluntariedad, la unilateralidad, la autorregulación y la no-exigibilidad que se vinculan a un modelo en el que la lucha de clases se sustituye por la corresponsabilidad entre empresariado, trabajadores y sociedad civil. En este marco, el control de las empresas transnacionales debe ajustarse a la mencionada corresponsabilidad, a la colaboración con las instituciones internacionales y a la armonía con los Estados y las empresas. Ante modificaciones tan extremas, la RSC se presenta como la alternativa más adecuada ${ }^{1}$ (Hernández, González y Ramiro, 2012).

\section{La arquitectura de los derechos: el Tratado de los Pueblos}

La Campaña Desmantelemos el Poder Corporativo hace años que viene denunciando la arquitectura jurídica de la impunidad que protege los derechos de las corporaciones transnacionales; es una legislación neoliberal creada paralelamente a los derechos de la ciudadanía y de los pueblos y, de facto, jerárquicamente superior a los mismos.

En esta línea y con el propósito de crear instrumentos para el ejercicio de un control real sobre las operaciones de estas compañías, diferentes movimientos sociales, pueblos originarios, sindicalistas, juristas, activistas y víctimas de las prácticas de las multinacionales acaban de elaborar el Tratado Internacional de los Pueblos para el control de las empresas transnacionales. La idea es que todo el trabajo colectivo que ha dado lugar a este tratado recoja la experiencia acumulada en la última década, a partir de las diferentes luchas contra las empre-

1 Tal y como recoge Dans (2015):

El caso Volkswagen representa, a todos los efectos, el fracaso absoluto de la Responsabilidad Social Corporativa (RSC). No hay paliativos posibles: hablamos de una manipulación consciente, conocida a todos los niveles de la compañía, intencionadamente diseńada para obtener un plus de competitividad con el que hacer frente a la pujanza de otros competidores, y que consiguió poner a la marca en el trono de su industria a nivel mundial al tiempo que se publicitaba como ecológica y envenenaba todo el planeta. 
sas transnacionales y las instituciones estatales e internacionales que las apoyan. Todo ello, con el objetivo de avanzar hacia el establecimiento de reglas vinculantes para las compañías transnacionales y la aprobación de normas que excluyan al sector privado de las áreas clave para la dignidad humana y la supervivencia del planeta.

El Tratado de los Pueblos es fruto de un proceso de luchas y resistencias de las comunidades, y en este sentido, es radical, alternativo y en continua consulta ${ }^{2}$; es un proceso de creación y recreación de propuestas y alternativas. Además, es una herramienta al servicio de la emancipación de los pueblos y de las personas, que coloca en el centro de su génesis el dolor de las víctimas. La impunidad con la que actúan las empresas multinacionales tiene impactos gravísimos sobre las personas, los pueblos y la naturaleza, y, por otra parte, las víctimas son invisibles e inexistentes, nunca se reflejan en las memorias de RSC de las empresas transnacionales (Campaña Desmantelemos el poder corporativo, 2014).

Los pueblos en resistencia y los movimientos sociales manejan muy bien los espacios y los tiempos; el tratado combina los principios y propuestas de largo alcance y de carácter estratégico con lo táctico, lo urgente e inmediato. Sus páginas basculan entre la utopía y la inmediatez, pero, en el marco de la confrontación y de la organización social.

Uno de sus objetivos reside en profundizar en el control de las corporaciones transnacionales y, para ello, promueve mecanismos de redistribución del poder político, económico y jurídico y fomenta el intercambio de propuestas y alternativas que consolidan alianzas entre movimientos.

Toma el testigo de la Declaración Universal de los Derechos de los Pueblos de Argel de $1976^{3}$ y propone alternativas que profundicen en la democracia y recuperen el espacio público. Propuestas que afirmen la soberanía ciudadana y se opongan a la cooptación empresarial en la toma de decisiones; que reinterpreten el comercio y las inversiones; que desafíen el poder financiero, recuperan los servicios públicos, las empresas estatales y democraticen el trabajo y la producción; propuestas que terminen con la división entre trabajo productivo y reproductivo.

El tratado también propone reconstruir la soberanía de los pueblos y los derechos colectivos mediante la reforma agraria, la agroecología, la soberanía alimentaria, la defensa de los derechos de los campesinos y las campesinas y la

\footnotetext{
2 Adjuntamos como anexo la declaración realizada en el País Vasco por un conjunto de sindicatos y movimientos sociales en el marco de los procesos de la Carta de los Derechos Sociales y Alternatiben Herria. En dicha declaración se ratifica el Tratado de los Pueblos. Sobre ambos procesos, ver: http://www.eskubidesozialenkarta.com/es/ y http://alternatibenherria.eus/?lang=es\#

3 Declaración Universal de los Derechos de los Pueblos, Argel, 4 de julio 1976 http://www.filosofia. org/cod/c1976pue.htm
} 
regulación del derecho humano al agua; formula la soberanía energética y defiende los territorios y los derechos de las comunidades frente al extractivismo y la «economía» verde; proclama el buen vivir de los pueblos indígenas.

Por último, integra e incorpora la economía solidaria, el ecologismo y el feminismo.

Desde la perspectiva jurídica, el tratado profundiza en el uso alternativo del derecho, que busca grietas interpretativas en el modelo hegemónico de dominación (Hernández y Ramiro, 2015a:116). De ahí, que pretenda reapropiarse y reelaborar los instrumentos legales clásicos, mediante propuesta concretas y específicas; evoluciona hacia un nuevo paradigma en la construcción de una nueva arquitectura de los derechos colectivos de los pueblos.

Su contexto es el de una larga lucha contra el Derecho Internacional, elaborado desde arriba, desde las élites políticas y económicas; ese derecho que nunca se ha preocupado de los movimientos sociales y de los pueblos, a los que ha considerado fuera del Estado y por tanto como sujetos ilegales e ilegítimos; ese derecho de las grandes corporaciones y de los acuerdos de comercio e inversiones, que se mueve en la armonía liberal capitalista de progreso y desarrollo (Rajagopal, 2005).

El tratado quiere un orden diferente, un derecho "desde abajo», desde los pueblos y para los pueblos, que conecte con la Carta de Argel de 1976 y que se vincule con las lógicas de resistencia y de construcción de normas internacionales elaboradas fuera de la opacidad y del secreto de la diplomacia al servicio del capital.

Hay que avanzar hacia una nueva constitución democrática internacional donde los pueblos sean sujetos constituyentes, actores de derecho y donde los Estados y el capital vayan cediendo espacios a los derechos humanos, colectivos y de la naturaleza. El tratado reinterpreta el cuadro de normas constituyentes.

En definitiva, es un proceso en continua evolución que enlaza alternativas jurídicas, económicas y sociales, en un proyecto político en confrontación con el capital y el patriarcado; contiene impulsos legales de corto alcance, junto a cambios de paradigma y de largo alcance, para quebrar el poder de las transnacionales cuya esencia es el capitalismo y la arquitectura de la impunidad.

Es un tratado de la solidaridad internacional, que profundiza en la construcción de redes contrahegemónicas y articula las resistencias en los ámbitos locales, nacionales, regionales y globales.

Por último, es el tratado de las víctimas provocadas por las prácticas de los Estados y las empresas transnacionales, víctimas a las que se pretende restituir, rehabilitar e indemnizar, con verdad, justicia y reparación. También se pretende establecer un fuero especial para los defensores de los damnificados que sufren amenazas y estrategias de coacción personal, familiar y legal. 


\subsection{Principios generales}

El Tratado Internacional de los Pueblos se vincula con una transformación radical del Derecho Internacional. Transformación que se ajusta, al menos, a las siguientes premisas sustanciales (Hernández, González y Ramiro, 2014: 17-20):

a) Los Estados no pueden ser el único eje sobre el que construir la legalidad internacional; son tiempos de los pueblos y de las personas. No podemos olvidar que el Derecho Internacional de los Derechos Humanos es el resultado de la lucha de millones de personas y miles de organizaciones de todo el mundo; la reapropiación y reelaboración de instrumentos legales clásicos es un desafío al paradigma dominante del orden jurídico-político. Así, el derecho a la consulta de los pueblos indígenas, regulado en el Derecho Internacional de los Derechos Humanos, se resignifica y se reconstruye en procesos asamblearios de consulta permanente. Los pueblos se caracterizan como sujetos constituyentes de la ley internacional, pueden proponer y proclamar nuevos derechos.

b) La supuesta fragmentación del Derecho Internacional en esferas separadas y supuestamente autónomas, permite a las empresas transnacionales y a los poderes corporativos imponer las reglas económicas y políticas del gran capital a las mayorías sociales. Se reinterpretan las normas internacionales a favor de los sectores dominantes. La inversión de la pirámide jurídica internacional es urgente e imprescindible y se requiere una nueva codificación normativa que exprese claramente que el Derecho Internacional de los Derechos Humanos —incluido el Derecho Internacional del Trabajo y el Derecho Internacional Ambiental- es jerárquicamente superior a las normas de comercio e inversiones, nacionales e internacionales, por su carácter imperativo y como obligaciones erga omnes, es decir de toda la comunidad internacional y para toda la comunidad internacional.

c) El Tratado Internacional de los Pueblos pretende progresar en la exigibilidad y justiciabilidad de los derechos de los pueblos, frente a la arquitectura de la impunidad que tutela los derechos de las empresas transnacionales (Hernández Zubizarreta, 2013); conceptos como la mera rendición de cuentas voluntaria y unilateral —que coloniza las Naciones Unidas - debe ser abandonada.

d) En cualquier caso, el Derecho Internacional de los Derechos Humanos establece una serie de principios que únicamente los intereses corporativos rechazan y reinterpretan a favor de las empresas transnacionales.

- Los derechos humanos, y el conjunto de normas para su aplicación, son universales, indivisibles e interdependientes.

- El Derecho Internacional de los Derechos Humanos se vertebra sobre la Declaración Universal de los Derechos Humanos, junto con el 
Pacto Internacional de Derechos Civiles y Políticos, el Pacto Internacional de Derechos Económicos, Sociales y Culturales y sus Protocolos Facultativos — que forman la Carta Internacional de Derechos Humanos-, así como sobre las declaraciones, directrices, observaciones y principios adoptados en el plano internacional.

— El sistema de fuentes del Derecho Internacional viene recogido en el artículo 38 del Estatuto de la Corte Internacional de Justicia y se encuentra constituido por las convenciones internacionales - generales o particulares - , la costumbre internacional, los principios generales del Derecho reconocidos por los sistemas jurídicos del mundo, en tanto fuentes principales y creadoras de las normas jurídicas, y las decisiones judiciales y las doctrinas de los juristas de mayor competencia, en tanto fuentes auxiliares y de interpretación de las normas existentes. En Derecho Internacional la costumbre tiene el mismo valor jurídico que los tratados internacionales y el Derecho Internacional consuetudinario está en vigor y es obligatorio. La Carta Internacional de Derechos Humanos forma parte del mismo y es una verdadera norma imperativa o de ius cogens que encarna y protege intereses esenciales de la comunidad internacional y que, según el Artículo 53 de la Convención de Viena sobre Derecho de los Tratados, establece que una norma imperativa no puede derogarse y no cabe acuerdo en sentido contrario por otra norma que no sea imperativa.

- Las empresas transnacionales y las Instituciones Internacionales Económico-Financieras deben respetar la soberanía de los pueblos y Estados en coherencia con el respeto al derecho al desarrollo, el buen vivir y los bienes comunes.

- Las empresas transnacionales, las Instituciones Internacionales y los Estados deben respetar y someterse a las prescripciones de las normas, recomendaciones y declaraciones que configuran el Derecho Internacional de los Derechos Humanos ${ }^{4}$.

\subsection{Propuestas concretas de regulación}

El contenido jurídico-político del Tratado Internacional de los Pueblos, recoge la doctrina establecida, en diferentes sentencias, por el Tribunal Permanente de los Pueblos. La responsabilidad de las empresas transnacionales por la violación sistemática de los derechos humanos se extiende a los Estados matrices, receptores y a las Instituciones Económico-financieras; el Tratado Internacional de los Pueblos aborda los cuatros vértices de responsabilidad. Es decir, no

\footnotetext{
4 El tema mencionado ha sido abordado por la doctrina desde diferentes vertientes; tres aportaciones recientes al respecto en Gutiérrez y Cervell (2012); Bonet (2013) y Zamora, García y Sales (2013).
} 
se refiere exclusivamente a la responsabilidad de las empresas transnacionales. Por otra parte, incluye el complejo ámbito de la autoría, complicidad, colaboración, instigación, inducción y encubrimiento.

El tratado establece la obligación de los Estados de proteger los derechos humanos contra las violaciones cometidas por las empresas transnacionales, detallando las medidas específicas que los Estados han de asumir al respecto. En concreto, estas deberían incluir el establecimiento de mecanismos efectivos a nivel nacional para posibilitar el acceso a la justicia y la reparación a las víctimas y las comunidades afectadas. Igualmente, los Estados deben garantizar que las grandes corporaciones que tienen su sede principal en su territorio respeten todos los derechos humanos cuando operan en el exterior; el tratado tendrá que especificar cuándo surgen tales obligaciones extraterritoriales, pero los Estados deberían, como mínimo, asumir el principio de extraterritorialidad cuando la transnacional tenga su centro de actividad, esté registrada, tenga su sede o desarrolle actividades económico-financieras en el Estado en cuestión.

El segundo apartado aborda las obligaciones específicas de las empresas transnacionales: las empresas transnacionales, sus filiales de hecho o de derecho y sus proveedores, subcontratistas y licenciatarios deben reconocer el principio de la primacía de los derechos humanos y del interés público sobre el interés económico particular; deben respetar la normas nacionales e internacionales que prohíban la discriminación, los derechos de las mujeres, las normas sobre migraciones y el medio ambiente; no pueden utilizar a su servicio las fuerzas armadas o de seguridad del Estado, ni contratar milicias privadas. En caso de contratación de servicios de seguridad privada, éstos deberán sujetarse a una estricta regulación que garantice el correcto ejercicio de sus funciones, las condiciones del uso de la fuerza, la necesaria supervisión por parte de las autoridades y no pueden actuar fuera del recinto de la empresa para la cual trabajan.

Además, el Tratado Internacional de los Pueblos trata, en los dos últimos apartados, los crímenes internacionales y las instancias de control.

Respecto a los crímenes internacionales contra la humanidad se pretende impulsar y profundizar en los delitos económicos, financieros y ecológicos como delitos contra la humanidad. Se propone aprobar nuevos tipos penales e instancias internacionales de control. Los crímenes internacionales deben extenderse a las políticas de ajuste, al pago de la deuda ilegal e ilegítima, a la explotación de los recursos naturales, a los delitos económicos que afecten de manera generalizada a una comunidad, a la especulación alimentaria, al trabajo infantil, etc. Las violaciones graves y masivas a los derechos económicos, sociales y culturales y los dańos graves al medio ambiente, causados deliberadamente o por negligencia culpable, deben tipificarse como crímenes económicos y ecológicos internacionales (FIBGAR, 2015). 
Así, las medidas tomadas por la troika están sometiendo a la ciudadanía griega a condiciones extremas, que pueden tipificarse como genocidio o crimen contra la humanidad. Las personas físicas responsables - los miembros del Consejo Europeo (presidentes y primeros ministros de la Unión Europea y presidente de la Comisión Europea), del Consejo de Administración del Fondo Monetario Internacional y del Consejo de Gobierno del Banco Central Europeo- pueden ser denunciadas ante la Corte Penal Internacional. Es posible invocar ante los tribunales como Derecho vigente el artículo 6 (genocidio; apartado c) y 7 (crímenes contra la humanidad; apartado k) del Estatuto de la Corte Penal Internacional (Roma 1998) contra los dirigentes arriba reseñados (Teitelbaum, 2010).

El Consenso de Washington hoy llamado Consenso de Bruselas, se sustenta sobre la trilogía de las privatizaciones, las desregulaciones y crisis de las instituciones del Estado de Bienestar. Las normativas comunitarias adoptadas colisionan con el principio de no regresividad en la satisfacción de los derechos sociales. El Pacto Internacional de Derechos Económicos Sociales y Culturales de 1996 establece que los poderes públicos deben emplear los recursos disponibles en favor de los derechos de las mayorías sociales. Vulnerar la prohibición de la regresividad es vulnerar el Pacto Internacional mencionado, norma de obligado cumplimiento ${ }^{5}$ (Hernández Zubizarreta y Ramiro, 2015c).

El último apartado referido a las Instancias aborda la necesidad de aprobar sistemas de control de las empresas transnacionales mediante el perfeccionamiento de los sistemas nacionales; la aprobación de la extraterritorialidad; la modificación de la jurisdicción universal; la aprobación de una Corte Mundial sobre Corporaciones Transnacionales, junto a la derogación de los paneles arbitrales internacionales para la resolución de conflictos entre empresas transnacionales y Estados.

\subsection{El Tratado de los Pueblos y los acuerdos de comercio e inversiones}

El tratado reafirma la primacía de los derechos humanos sobre los tratados comerciales y de inversión. Además, considera que cualquier acuerdo de comercio e inversiones requiere una evaluación previa de sus posibles impactos y una

5 El Comité de Derechos Económicos, Sociales y Culturales en su 48. ${ }^{\circ}$ período de sesiones - 30 de abril a 18 de mayo de 2012-:

Insta al Estado parte - España - a que, en virtud del principio de indivisibilidad, universalidad e interdependencia de los derechos humanos, adopte las medidas legislativas pertinentes para garantizar a los derechos económicos, sociales y culturales un nivel de protección análogo que el que se aplica a los derechos civiles y políticos. Asimismo, el Comité recomienda al Estado parte que tome las medidas adecuadas para asegurar la plena justiciabilidad y aplicabilidad de todas las disposiciones del Pacto por los tribunales nacionales. 
consulta popular, ya que sus contenidos afectan al conjunto de la ciudadanía (Hernández Zubizarreta y Ramiro, 2015d).

Desde una perspectiva jurídica, los principios jurídicos vinculados a las normas de libre comercio e inversión — trato nacional, nación más favorecida, trato más favorable, trato justo y equitativo, el concepto de inversión, el concepto de expropiación indirecta, la limitación a exigirles requisitos de desempeño, la protección retroactiva del tratado, la libre disponibilidad de divisas, la cláusula paraguas, las cláusulas de estabilización y la cláusula de sobrevivencia posterior a su denuncia, etc. - deben subordinarse a las normas nacionales del Estado receptor y a las normas internacionales de derechos humanos. En ningún caso debe permitirse que las disputas entre inversionista-Estado se sometan a la decisión de órganos arbitrales, ya que implican un menoscabo de la protección ya concedida a la soberanía de los Estados, a los derechos de las personas y los pueblos por el Derecho Internacional de los Derechos Humanos.

Por otra parte, los usos y principios internacionales universales - tales como: lo pactado por las partes debe ser cumplido (pacta sunt servanda), los principios de equidad, buena fe, abuso de derecho, enriquecimiento injusto, el cambio fundamental de circunstancias modifica las obligaciones de las partes (rebus sic estantitbus), fuerza mayor y estado de necesidad- deben interpretarse de manera conjunta, complementaria y a favor de los derechos de las mayorías sociales; la seguridad jurídica de las inversiones no debe interpretarse como equivalente al principio pacta sunt servanda, sino como exigencia de respeto al conjunto de los principios mencionados. El principio internacional de primacía en favor de las víctimas debe prevalecer sobre las normas de comercio e inversiones.

Por último, la incorporación de cláusulas sociales, laborales y medioambientales en los tratados y acuerdos de comercio e inversiones son disposiciones más declarativas que imperativas; son cláusulas subordinadas a la protección del comercio y de las inversiones. Debe modificarse su valor normativo, de manera que las cláusulas sean jerárquicamente superiores a los principios vinculados a las normas de comercio e inversiones y suprimir las normas sobre comercio e inversión incompatibles con el pleno respeto de todos los derechos humanos integralmente considerados.

El tratado también incide en como los bienes públicos esenciales deben quedar fuera del comercio y de las inversiones y bajo tutela pública y colectiva: así, el agua, la salud, la educación, los servicios públicos... Además, se debe fomentar el desarrollo local y las empresas de economía social y solidaria. 


\section{Bibliografía}

BALAKRISHNAN, Rajagopal (2005): El Derecho Internacional desde abajo, Bogotá, ILSA Instituto Latinoamericano de servicios legales alternativos.

BONET, Jordi (2013): El Derecho Internacional de los derechos humanos en periodos de crisis. Estudios desde la perspectiva de su aplicabilidad, Madrid, Marcial Pons.

CAMPAÑA DESMANTELEMOS EL PODER CORPORATIVO (2014): ¿Qué es el Tratado de los Pueblos?. En: http://www.stopcorporateimpunity.org/?page_ $\mathrm{id}=5574 \&$ lang=es

DANS, Enrique (2015): «El caso Volkswagen y el fracaso de la Responsabilidad Social Corporativa», Enrique Dans, 26 de septiembre. En: http://www.enriquedans.com/2015/09/el-caso-volkswagen-y-el-fracaso-de-la-responsabilidad-socialcorporativa.html

FIBGAR (2015): Principios Madrid-Buenos Aires de Jurisdicción Universal, crimenes económicos y medioambientales, Madrid, FIBGAR. En: http://fibgar.org/upload/ proyectos/35/es/principios-de-jurisdiccion-universal.pdf

GUTIÉRREZ, Cesáreo y CERVELL, María José (2012): El Derecho Internacional en la encrucijada, Trotta, Madrid.

HERNÁNDEZ CERVANTES, Aleida (2014): La producción jurídica de la globalización económica. Notas de una pluralidad jurídica transnacional, México D.F, Universidad Nacional Autónoma de México (UNAM).

HERNÁNDEZ ZUBIZARRETA, Juan (2015): "The new global corporate law», en State of Power 2015, Ámsterdam, Transnational Institute. En: http://www.tni.org/ sites/www.tni.org/files/download/01_tni_state-of-power-2015_the_new_global_ corporate_law-1.pdf

HERNÁNDEZ ZUBIZARRETA, Juan y RAMIRO, Pedro (2015a): Contra la Lex Mercatoria. Propuestas y alternativas para controlar a las transnacionales, Barcelona, Icaria.

HERNÁNDEZ ZUBIZARRETA, Juan y RAMIRO, Pedro (2015b): «¿Qué fue del Plan Nacional sobre Empresas y Derechos Humanos?», La Marea, 20 de febrero. En: http://www.lamarea.com/2015/02/20/que-fue-del-plan-nacional-sobre-empresas-yderechos-humanos/

HERNÁNDEZ ZUBIZARRETA, Juan y RAMIRO, Pedro (2015c): «Las responsabilidades del Banco Mundial, el FMI, la Comisión Europea y el BCE», La Marea, Madrid, http://www.lamarea.com/2015/05/29/las-responsabilidades-del-banco-mundial-elfmi-la-comision-europea-y-el-bce/

HERNÁNDEZ ZUBIZARRETA, Juan y RAMIRO, Pedro (2015d): «El TTIP contra el Derecho internacional de los Derechos Humanos", La Marea, 17 de abril. En: http://www.lamarea.com/2015/04/17/el-ttip-contra-el-derecho-internacional-de-losderechos-humanos/

HERNÁNDEZ ZUBIZARRETA, Juan y RAMIRO, Pedro (2014): «El poder corporativo transnacional frente al soft law: plan nacional sobre empresas y derechos humanos, debates y propuestas» en Carmen Márquez Carrasco (ed.), España y la implementación de los Principios Rectores de las Naciones Unidas sobre empresas y derechos humanos: oportunidades y desafios/ Spain and the Implementation of the United Nations Guiding Principles on Business and Human Rights: Challenges and Opportunities, Barcelona, Editorial Huygens.

HERNÁNDEZ ZUBIZARRETA, Juan, GONZÁLEZ, Erika y RAMIRO, Pedro (2014): Tratado Internacional de los Pueblos para el Control de las Empresas Trans- 
nacionales. Una apuesta desde los movimientos sociales y la solidaridad internacional, Bilbao, Hegoa. En: http://publicaciones.hegoa.ehu.es/assets/pdfs/325/Cuadernos_ Hegoa_n\%C2\%BA64.pdf?1418916916

HERNANDEZ ZUBIZARRETA, Juan (2013): «Arquitectura jurídica de la impunidad», Diagonal, 22 de noviembre. En: https:/www.diagonalperiodico.net/global/20852arquitectura-juridica-la-impunidad.html

HERNÁNDEZ ZUBIZARRETA, Juan, GONZÁLEZ, Erika y RAMIRO, Pedro (2012): Diccionario critico de empresas transnacionales. Claves para enfrentar el poder de las grandes corporaciones, Barcelona, Icaria.

HERNÁNDEZ ZUBIZARRETA, Juan (2009): Las empresas transnacionales frente a los derechos humanos. Historia de una asimetría normativa, Bilbao, Hegoa y OMAL.

TEITELBAUM, Alejandro (2010): La armadura del capitalismo, Barcelona, Icaria.

ZAMORA, Francisco, GARCÍA Jesús y SALES, Lorena (2013): La responsabilidad de las multinacionales por violaciones de derechos, Madrid, Universidad de Alcalá y Cátedra de democracia y derechos humanos.

\section{ANEXO}

Bilbao, 24 de octubre de 2015

\section{Ante la amenaza del TTIP y el TISA, solidaridad de los pueblos}

\section{Otro mundo es posible}

Otro modelo de relaciones entre los pueblos es necesario y desde aquí queremos contribuir a que se haga realidad. Y lo hacemos desde nuestro compromiso con principios básicos de lucha y movilización como los recogidos en la Carta de los Derechos Sociales de Euskal Herria.

A Euskal Herria, como a cualquier otro pueblo, le corresponde el derecho a decidir su propio modelo económico, social, político e institucional sin más límites que la voluntad democráticamente expresada por la ciudadanía vasca. Y deben ser sus instituciones, con participación social activa, las que garanticen estos derechos sociales básicos para cuantas personas viven y trabajan en Euskal Herria.

Hay que cambiar las prioridades de la acción política, económica e institucional y poner a las personas y sus intereses por encima de los intereses del mercado, y el derecho al trabajo productivo y reproductivo por encima de los intereses del capital.

La razón última de cualquier actividad económica no puede ser el enriquecimiento particular a costa del empobrecimiento general. Para ello hay que asegu- 
rar la eficiencia social de la política económica: los derechos sociales básicos deben ser la prioridad de acción de todo gobierno.

Los servicios públicos están obligados a la defensa del bien común. Su objeto es garantizar el ejercicio de los derechos sociales de la población vasca de manera igualitaria, accesible, descentralizada y eficiente con medios propios.

Estos principios básicos de actuación recogidos en la Carta de los Derechos Sociales de Euskal Herria, no sólo son negados por las instituciones neoliberales que nos gobiernan, sino que nuevas amenazas pretenden hacer imposible su materialización.

Los poderosos tratan de apuntalar su posición de dominio mediante tratados internacionales que, como el TTIP y TISA, otorgan al capital financiero y las multinacionales las garantías jurídicas necesarias para controlar en su propio beneficio la economía, el ecosistema, los derechos y las capacidades de las personas y la propia vida. La democracia es sustituida por la dictadura del capital y todas las personas pasan a ser deudores de un sistema regido por rentistas y especuladores. Los Tratados de Libre Comercio se nos quieren imponer con licencia para arrasar soberanías (alimentarias, energéticas, políticas, democráticas) y derechos laborales, sociales, de salud, medioambientales...

Por ello nos oponemos firmemente a la proliferación de tratados internacionales que traen destrucción, robo, desigualdad, pobreza... Desde Euskal Herria proclamamos que otro mundo es posible, que otro modelo de relaciones internacionales, solidario, justo, cooperativo y basado en la soberanía de los pueblos para decidir su futuro es imprescindible.

Desde estas premisas, y desde el reconocimiento pleno a la libre autodeterminación de los pueblos, nos sentimos parte de la Campańa Global para desmantelar el Poder Corporativo y poner fin a la impunidad del poder y las vulneraciones de derechos de las Corporaciones Transnacionales.

Hacemos nuestras las propuestas para desafiar al poder financiero, recuperar los servicios públicos, democratizar el trabajo y la producción, defender la soberanía alimentaria y los derechos de los campesinos y campesinas, regular el derecho humano al agua, garantizar la soberanía energética frente al extractivismo y defender el buen vivir de los pueblos indígenas.

Exigimos poner fin al entramado de normas, convenios y tratados que protegen el poder de las empresas transnacionales; construir una nueva arquitectura de los derechos sociales, que frene las violaciones de derechos humanos cometidas por las empresas trasnacionales; crear marcos para el intercambio, y la creación de alianzas entre comunidades, movimientos sociales y sindicatos. 
Por todo ello, frente a tratados como el TTIP y TISA, nos adherimos al Tratado Internacional de los Pueblos para el control de las empresas transnacionales como instrumento internacional jurídicamente vinculante que:

- Detalla la obligación de las empresas transnacionales, de respetar todos los derechos humanos, especialmente: el derecho a la vida, la libertad de asociación, la libertad de opinión y expresión, el derecho a la no discriminación, al trabajo, la alimentación, el derecho al agua, al alojamiento, la salud, el derecho a la autodeterminación y el derecho a un medio ambiente sano.

- Regula la responsabilidad solidaria de las empresas transnacionales por las actividades violatorias de los derechos humanos de sus filiales, de hecho o de derecho, y de sus proveedores, subcontratistas y licenciatarios.

- Afirma la obligación de las Instituciones Públicas de proteger los derechos humanos contra las violaciones cometidas por las empresas transnacionales, detallando las medidas específicas que han de asumir al respecto.

- Reafirma la primacía de los derechos humanos sobre los tratados comerciales y de inversión.

- Establece la responsabilidad civil y penal de las empresas y sus directivos.

— Incluye obligaciones para las instituciones internacionales económico-financieras.

- Establece patrones que permiten el reconocimiento de nuevos crímenes económicos y medioambientales internacionales.

- Aprueba mecanismos internacionales para hacer cumplir el Tratado, como la creación de una Corte Internacional sobre transnacionales y derechos humanos.

Frente al capital financiero y las multinacionales, frente a sus Tratados de muerte, abramos otro camino: el de la vida y la solidaridad entre los pueblos.

Frente a la Europa de las multinacionales, construyamos la Europa Social y de los pueblos.

Bilbo, 24 de octubre de 2015

\section{TTIP eta TISAren mehatxuari aurre egiteko, herrien elkartasuna}

\section{Bestelako mundu bat posible da}

Herrien arteko harremanetarako beste eredu bat beharrezkoa da, eta hemendik gauzatzen laguntzeko prest gaude, gure konpromisoari eutsiz, hots, Euskal Herriko Eskubide Sozialen Kartan jasotako borroka eta mobilizazio oinarrizko printzipioen arabera. 
Euskal Herriari, beste edozein herriri bezala, bere eredu ekonomiko, sozial, politiko eta instituzionala erabakitzea dagokio, euskal herritarrek demokratikoki adierazitako borondatea beste mugarik gabe. Eta bere instituzioek bermatu egin behar dituzte, jendartearen parte hartze aktiboarekin, oinarrizko eskubide sozial horiek Euskal Herrian bizi diren eta lan egiten duten pertsona guztientzat.

Ekintza politiko, ekonomiko eta instituzionalaren lehentasunak aldatu behar dira, pertsonak eta hauen interesak merkatuaren interesen aurretik jarri, eta lan produktibo zein erreproduktiborako eskubidea kapitalaren interesen gainetik.

Edozein jarduera ekonomikoren arrazoi nagusia ezin daiteke izan pobretze orokorrari esker banakoa aberastea. Horretarako politika ekonomikoa ikuspuntu sozialetik eragingarria izango dela ziurtatu behar da: oinarrizko eskubide sozialak gobernu ororen lehentasuna izan behar dira.

Zerbitzu publikoen betebeharra da ongizate komunaren defentsa. Hau da, euskal biztanleriak dituen eskubide sozialak bermatu behar dituzte, berdintasunez, modu irisgarri, dezentralizatu eta eragingarrian, eta beren bitartekoak baliatuaz.

Agintean dauden erakunde neoliberalek ukatu egiten dituzte Euskal Herriko Eskubide Sozialen Kartan jasota dauden oinarrizko jardunbide hauek, eta gainera beste mehatxu batzuk agertu dira, haiek gauzatzeko traba bihurtzen direnak.

Boteretsuek beren nagusitasuna sendotu nahi dute TTIP eta TISAren moduko nazioarteko itunen bidez; hauek kapital finantzarioari eta multinazionalei berme juridikoa eskaintzen diete, beren mesedetan kontrolatzeko ekonomia, ekosistema, pertsonen eskubide eta gaitasunak, baita bizitza bera ere. Demokraziaren ordez kapitalaren diktadura ezartzen da, eta pertsona guztiak zordun bihurtzen dira errentista eta espekulatzaileen agintepean dagoen sistema batean. Merkataritza Libreko Itunak inposatu nahi dizkigute, hainbat arlotako burujabetza deuseztatzeko lizentzia dutelarik (elikagai, energia, politika eta demokraziari dagokienez), edota eskubide laboral, sozial, osasun eta ingurumenekoak barne...

Horregatik ez dugu inola ere onartzen halako nazioarteko hitzarmenik, suntsipena, lapurreta, desberdintasuna eta txirotasuna baitakarte. Euskal Herritik aldarrikatzen dugu bestelako mundu bat posible dela; areago, ezinbestekoa dela nazioarteko harremanen beste eredu bat, zeinen ardatzak solidaritatea, justizia eta lankidetza izango diren, eta oinarritzat herriek beren etorkizuna erabakitzeko burujabetza hartzen duen.

Abiapuntu horiekin, herrien autodeterminazio askea bete-betean aitorturik, Botere Korporatiboa desegiteko eta Korporazio Transnazionalen botere zigorgabea zein eskubide urraketa amaiarazteko munduko Kanpainaren partetzat hartzen dugu geure burua. 
Geure egiten dugu hainbat proposamen: Botere finantzarioari aurre egitea, zerbitzu publikoak berreskuratzea, lana eta produkzioa demokratizatzea, elikadura-burujabetza eta nekazarien eskubideak defendittzea, ura izateko giza-eskubidea arautzea, burujabetza energetikoa bermatzea estraktibismoaren aurka, eta herri indigenen bizimodu egokiaren alde egitea.

Enpresa transnazionalen boterea babesten duten arau, itun eta hitzarmenen sarea bertan desager dadila exijitzen dugu; eskubide sozialen arkitektura berri bat eraikitzea, enpresa transnazionalek eragindako giza-eskubideen urraketa geldiarazteko; elkartrukerako eremuak sortzea, eta komunitate, mugimendu sozial eta sindikatuen arteko aliantzak eratzea.

Horregatik, TTIP eta TISAren moduko hitzarmenak alde batera utzi eta bat egin nahi dugu Enpresa Transnazionalak kontrolatzeko Herrien Nazioarteko Itunarekin; hau nazioarte mailako tresna lotesletzat hartzen dugu, honako ezaugarriekin:

- Zehazten du enpresa transnazionalek giza-eskubide guztiak errespetatu behar dituztela, batik bat honakoak: bizitzeko eskubidea, elkartzeko askatasuna, iritzi eta adierazpen askatasuna, diskriminaziorik ez pairatzeko, lanerako eta elikadurarako eskubidea, ura izateko, bizilekurako, osasunerako eskubidea, autodeterminaziorako eskubidea eta ingurumen osasuntsu baterako eskubidea.

- Arautzen du enpresa transnazionalei erantzukizun solidarioa dagokiela beren filialek giza-eskubideak urratzen badituzte, izatez zein zuzenbidez, baita beren hornitzaile, azpikontrata eta lizentziadunen kasuan ere.

- Herri-erakundeek babestu egin behar dituzte enpresa transnazionalek urra ditzaketen giza-eskubideak, honi buruz hartu behar dituzten erabakiak zehaztuaz.

- Berretsi egiten du giza-eskubideen lehentasuna merkataritza- eta inbertsio-hitzarmenekiko.

- Enpresen eta hauen buruen erantzukizun zibil eta penala zehazten du.

- Nazioarteko erakunde ekonomiko-finantzarioen betebeharrak jasotzen ditu.

— Nazioarteko krimen ekonomiko eta ekologiko berriak ezagutzeko patroiak ezartzen ditu.

- Hitzarmena betearazteko nazioarteko mekanismoak onartzen ditu, esaterako Transnazionalei eta Giza-Eskubideei buruzko Nazioarteko Auzitegia.

Kapital finantzarioaren eta multinazionalen aurka, urra dezagun beste bide bat: biziarena, herrien arteko elkartasunarena. rriena.

Multinazionalen Europaren aurka, eraiki dezagun Europa Soziala eta he- 